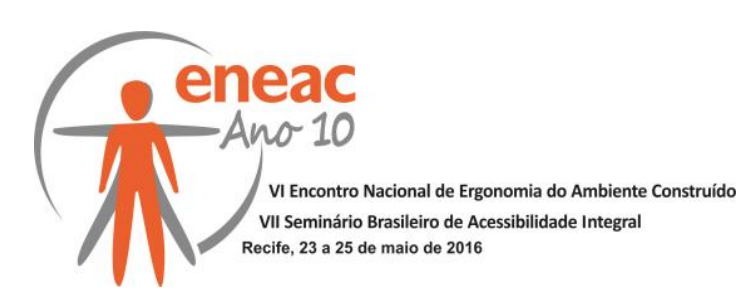

\title{
ACESSIBILIDADE INTEGRAL COMO FERRAMENTA DE INCLUSÃO SOCIAL: Estudo de caso em casas de acolhimento para crianças e adolescentes em situação de vulnerabilidade social
}

\author{
SAVI, Aline Eyng (1); \\ DISCHINGER, Marta (2) \\ (1) Universidade Federal de Santa Catarina, Mestre. \\ e-mail: arquiteta.alinesavi@gmail.com \\ (2) Universidade Federal de Santa Catarina, PhD. \\ e-mail: martadischinger@gmail.com
}

\begin{abstract}
RESUMO
O Estatuto da Criança e do Adolescente criou modalidades de assistência, entre elas: acolhimento institucional. Esse é o modelo mais comum, acolhendo ambos os sexos, entre zero e dezoito anos, em processo ou não de adoção. A legislação controla a administração, mas é generalista quanto ao ambiente construído. Uma possibilidade é estuda-lo a partir da acessibilidade integral com observações qualitativas do usuário. Objetiva-se: descrever as atividades; diagnosticar as necessidades e os problemas; e propor recomendações. Os métodos foram: Observação, Levantamento Arquitetônico e Entrevistas. Através da acessibilidade integral contribuir-se-ia para a construção de uma identidade, sem a qual não há inclusão.
\end{abstract}

Palavras chave: Ambiente Construído; Acessibilidade integral; Acolhimento institucional.

\begin{abstract}
The Statute of Children and Adolescents established aid modalities, including: shelter. The shelter is the most common model. It houses children and adolescents of both sexes, aged between zero and eighteen, in the process of adopting or not. The legislation controls the administration, but it is general as the built environment. One possibility is to study the built environment from the accessibility to comprehensive and qualitative user comments. The goal is to describe the activities; diagnose the needs and problems; and propose recommendations. The methods used were observation, Architectural Survey and Interviews. The full accessibility contribute to the construction of an identity, without which no inclusion.
\end{abstract}

Keywords: built environment; accessibility; shelter.

\section{INTRODUÇÃO}

Na história social brasileira, a infância e a adolescência foram tradicionalmente assistidas sob os princípios de vigilância e repressão. A aprovação do Estatuto da Criança e do Adolescente (ECA) em 1990 e a lei $n^{\circ} 12.010$ de 2009 tentaram mudar o quadro e assegurar a proteção integral, criando várias modalidades de assistência entre elas o acolhimento institucional. 


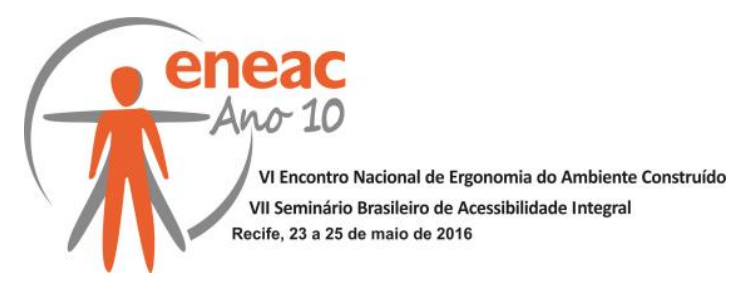

Esse é o modelo mais comum no Brasil atualmente. Acolhe crianças e adolescentes de ambos os sexos, entre zero e dezoito anos incompletos, em processo de adoção ou não, com ou sem família próxima ou estendida. Não implica em reclusão e salvaguarda o direito à saúde, educação, moradia e alimentação. O motivo para o acolhimento é variado, mas se relaciona ao quadro de vulnerabilidade social.

A institucionalização é um momento difícil na vida dos internos. Eles deixam suas famílias e vivem sob a tutela do Estado até que os motivos do acolhimento sejam sanados. A situação deve ser transitória, mas por diferentes razões, a maior parte dos casos leva meses ou anos para se resolver. A realidade é de crianças e adolescentes que passam parte expressiva de suas vidas institucionalizados, ou fazem o processo de ida e volta, entre instituição e família, apesar das iniciativas legais para minimizar a situação.

A legislação brasileira controla a administração desses locais, mas é generalista quanto ao ambiente construído. Há apenas o artigo 92 do ECA e os Códigos de Obras municipais referentes à higiene e salubridade. Todos limitados no tocante a questões de sua usabilidade. O resultado são instituições em edificações alugadas, adaptadas ao uso, muitas vezes sem referência de uma casa, em razão da coletividade dos ambientes e das funções administrativas ali realizadas.

Acredita-se que a situação de provisoriedade almejada pela legislação brasileira seja um dos motivos para que não haja reflexões mais profundas sobre o ambiente construído onde ocorre o acolhimento. Por outro lado, é a realidade de longa permanência que justifica a necessidade de estudar a situação também sob a ótica do ambiente construído. Afinal, a organização das estruturas do arranjo espacial obedece a regras, veladas ou não, que visam garantir o seu funcionamento, e ao mesmo tempo comunicam valores da cultura que os gerou. Agindo como sistemas de comunicação estas regras vinculam diversas manifestações do imaginário coletivo ou, como diz Rapoport (1982), diretrizes para o comportamento social.

Dessa maneira, acredita-se que é iminente a necessidade de entender como o espaço da edificação é vivenciado pelas crianças e pelos adolescentes. Há na instituição a possibilidade dela ser um sistema de comunicação de abrigo (proteção física) ou de casa (proteção física carregada de símbolos). Cada uma dessas palavras comunica um valor, que será interiorizado por toda a sua vida, podendo ser: "a criança do abrigo" ou "a minha casa".

Enquanto mudanças de cunho social não suprem as variáveis que colocam a criança e o adolescente em situação de vulnerabilidade, a instituição pode repetir (mesmo que sem intenção) práticas históricas excludentes. Hoje o objetivo almejado no acolhimento é o atendimento individual, em pequenos grupos, mas nada garante que isso permita a vivência como numa casa, condição esta fundamental para o crescimento e desenvolvimento humano saudável.

Para alcançar tal concepção do acolhimento institucional, uma das visões possíveis é estudar o ambiente construído a partir do conceito de acessibilidade de uma forma ampla e abrangente. Compreendendo-o como a medida de atitudes, com observações qualitativas da opinião do usuário que interage, quantificando a sua satisfação ao usa-lo (NEWEL; CAIRNS, 1993). Na casa de acolhimento, é a possibilidade das crianças e adolescentes fazerem parte das atividades que acontecem no cotidiano da instituição em que vivem - e não vivenciar o período do acolhimento como um ato de suspensão da vida cotidiana.

Para que se alcance a acessibilidade de forma abrangente é preciso que os ambientes sejam adequados não só às necessidades funcionais, mas também às necessidades psicossociais de seus usuários. O termo, sob este prisma, pode colaborar na participação com segurança, conforto e autonomia nas diversas atividades da instituição, contribuindo para o resgate do sentimento de lugar e de casa, e fora dos limites físicos fornecer mecanismos para a inclusão social, através da atuação política (NEWEL; CAIRNS, 1993). 


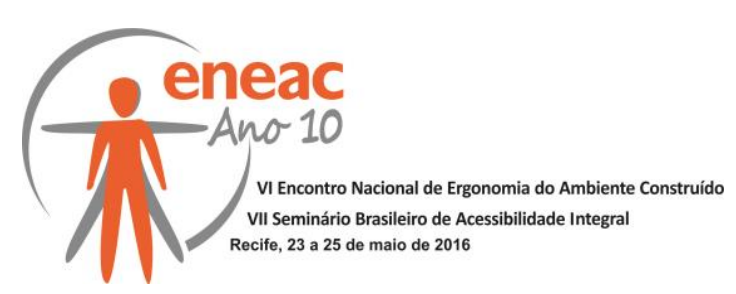

Este trabalho é parte de tese de Doutorado a ser defendida cujo objetivo geral é: "Compreender e caracterizar o ambiente construído da instituição de acolhimento para refletir como as características e as regras de uso podem contribuir ou não para a inclusão, almejada pela Legislação brasileira". As reflexões desse artigo objetivam: (1) detectar e descrever as atividades cotidianas; (2) diagnosticar as necessidades e os problemas encontrados pelos usuários nas atividades cotidianas em seus múltiplos âmbitos; e (3) propor sugestões e recomendações projetuais para viabilizar as atividades realizadas. Nesse artigo, o foco está na avaliação das atividades, apresentando análise espacial que compreende a parte funcional.

Esta avaliação é ainda mais necessária se considerarmos que as condições do ambiente construído podem constituir fatores de risco ou de saúde. A instituição consiste na substituição, provisória ou não, da estrutura física de casa e psicológica de família. Sabe-se que o contexto ambiental onde a criança e o adolescente crescem e se desenvolvem é crucial nas causas e manifestações dos problemas, especialmente nas questões de comportamento. De acordo com Okamoto (2002) este deve oferecer condições de acessibilidade para o usuário participar e interagir, desenvolvendo novas competências cognitivas e sociais. O ambiente construído com acessibilidade em seu sentido mais amplo, como definido por Milton Santos (1987) pode constituir um elemento importante para estimular e favorecer o estabelecimento dos primeiros conceitos de cidadania e respeito às diferenças humanas, promovendo a inclusão social.

\section{PROCEDIMENTOS METODOLÓGICOS}

É preciso esclarecer que as dinâmicas das relações existentes nas casas de acolhimento normalmente são pouco conhecidas pelos profissionais arquitetos. Mas, se é desejo na Arquitetura a interferência em uma realidade para adequação à finalidade que se destina visando qualidade de vida do seu usuário, é necessário que sejam aprofundados esses conhecimentos.

Nessa perspectiva, para desenvolver estudos de acessibilidade de forma integral, é necessário ampliar o olhar e incluir outros elementos na avaliação do espaço que permitam examinar condições de apropriação e de verdadeiro acolhimento.

Consequentemente, nessa pesquisa, os estudos de acessibilidade baseiam-se na aplicação conjunta de vários conhecimentos para alcançar dados sobre o homem e suas relações com o ambiente construído, visando melhor adaptá-lo. Neste sentido, são utilizados os estudos de acessibilidade espacial que se aproximam da ergonomia, que é o estudo do comportamento humano frente às interfaces. Os elementos do ambiente considerados pela ergonomia são aqueles referentes ao conforto, à percepção ambiental, aos materiais de revestimentos e acabamentos e aos postos de trabalho - layout e mobiliário - considerando, também, os dados antropométricos (RIBEIRO; MONT'ALVÃO, 2004).

Além destes fatores objetivos busca-se ampliar o conceito e a percepção da qualidade do lugar numa abordagem holística, capaz de responder aos desafios de criar ambientes comprometidos com a valorização e a promoção do desenvolvimento das múltiplas dimensões humanas. Escutar a(s) voz(es) das crianças e dos adolescentes se constitui no plano epistemológico. Por um lado, porque se assume como legítimas as suas formas de comunicação e relação, considerando relevante que o que têm a dizer. Por outro, por que é reconhecido o papel dos usuários-sujeitos-pesquisados para a produção de uma Arquitetura capaz de produzir uma estrutura espaço-temporal cada vez mais adequada à ação humana, alcançando acessibilidade integral. 


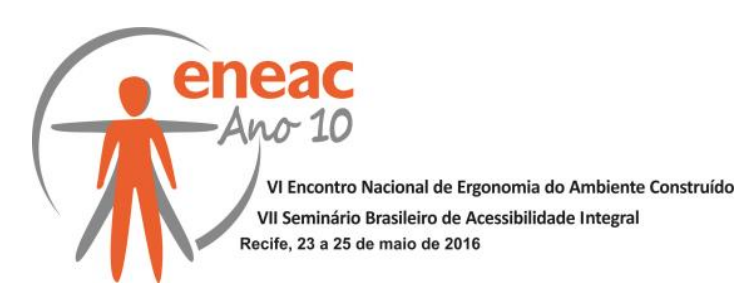

Em face da complexidade do objeto de estudo, o objetivo central no desenvolvimento dos instrumentos de avaliação é construir embasamento para a reflexão principal da tese. Até o momento, a pesquisa avaliou os dormitórios, face à relevância destes espaços em estudos sobre a privacidade. Numa casa, o conceito é um dos principais reguladores espaciais para que se construa o sentimento de pertencimento, independente da situação de provisoriedade ou não.

A obtenção dos dados exigiu a combinação de três diferentes métodos de investigação: Observação, Levantamento Arquitetônico e Entrevistas, que resultaram na leitura espacial e serviram para coletar informações de fonte primária (crianças e adolescentes). Os diferentes instrumentos são descritos resumidamente nos parágrafos seguintes.

A observação foi não participante com a elaboração de relatório escrito de fatos e fenômenos referentes às atividades cotidianas realizadas e a acessibilidade integral interações entre usuário-ambiente e usuário-usuário, que serviram de embasamento para as leituras das características de uso e apropriação. Para complementar, foram feitos registros de vídeos e fotos.

O levantamento arquitetônico foi realizado a partir de planilhas. Elas orientaram na descrição dos seguintes itens: arranjo espacial e os atributos que permitiam acessibilidade integral, correspondendo à: interações entre usuário-ambiente e usuário-usuário; o mobiliário e seu estado de conservação; a qualidade dos materiais de acabamento (piso, parede e teto). Relataram-se as características e o grau dos danos destes elementos, bem como as características gerais dos usuários para análise ergonômica. Para auxiliar na aplicação da planilha foram utilizadas as técnicas de registro fotográfico e medição in loco. Os registros em tópicos na planilha foram, posteriormente, transcritos.

As entrevistas foram não estruturadas, seguindo Marconi e Lakatos (1996). A escolha do instrumento deu-se porque as perguntas abertas se moldavam às diferentes situações e respostas. Através destas entrevistas, os usuários puderam relatar suas impressões e expectativas quanto ao espaço. Tais relatos foram utilizados para confirmar os pontos positivos e negativos levantados pelos demais instrumentos.

Além dos métodos utilizados, o artigo apresenta parte da revisão de literatura da tese, apresentando os seus principais conceitos. Esta revisão é importante para fundamentar a compreensão dos temas abordados e foi realizada através de documentação indireta recolhendo informações prévias acerca do estado da arte na área de interesse da pesquisa. Convencionou-se chamar de revisão de literatura porque não se limita ao estudo de livros e publicações impressas, mas ao meio eletrônico, em sites e portais de publicações científicas. É importante salientar a interdisciplinaridade intencional da pesquisa.

\section{AMBIENTE CONTRUÍDO}

O homem sempre planejou, moldou e construiu o espaço para as atividades de abrigar e sociabilizar, com o intuito de suprir suas necessidades vitais, conceituados como "construídos". Assim, "ambiente construído" pode ser definido como "[...] a criação do espaço vivencial, tanto para o indivíduo quanto para o meio social, onde se está em permanente deslocamento de uma atividade para outra" (OKAMOTO, 2002, p. 149). Ele aparece como um modelo social de organização da atividade humana, operando ao mesmo tempo como instrumento funcional e contexto cultural. Essa função numa moradia, por exemplo, não equivale apenas ao abrigo, mas à expressão das emoções e da vivência desenvolvida pelo sentimento "de estar e sentir-se em casa". 


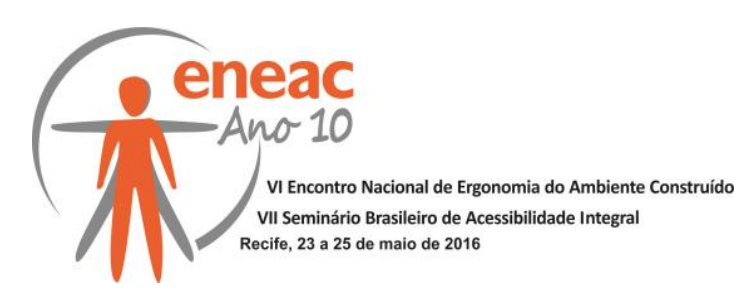

O ambiente construído como o arranjo de características físicas e construtivas é indissociável do ambiente social. É considerado espaço de vida, sujeito à ocupação, leitura, reinterpretação e/ou modificação pelos usuários. O ambiente construído interage com 0 ambiente social, cultural e psicológico. É fruto do comportamento humano e resultado de uma série de padrões e normas sociais que, por consequência, influenciarão as atividades ali realizadas (OKAMOTO, 2002).

No ambiente construído, os elementos objetivos são: forma, função, cor, textura, aeração, temperatura ambiental, iluminação, sonoridade. Cada um desses valores resulta no espaço dimensionado, funcional e significante. "Por meio deles, sentimos o ambiente e os fatos e eventos que nos chamam a atenção ou que selecionamos como de interesse, quando, então, temos a percepção da realidade de forma consciente [...]" (OKAMOTO, 2002, p. 106).

No projeto de ambientes para crianças e adolescentes, é preciso avaliar cuidadosamente vários aspectos espaciais. Os ambientes bem projetados, segundo Trancik e Evans (1995), podem aumentar a competência dos usuários na apropriação ambiental, permitindo que façam uso das suas capacidades, ao mesmo tempo em que são estimulados a desenvolver habilidades mais complexas, além do nível de desenvolvimento em que estejam. Afinal, a criança e o adolescente têm necessidades de se apropriar do ambiente, ao contrário de serem intimidados ou dominados. Eles precisam de liberdade para explorar e testar suas habilidades.

A ligação a um lugar é componente principal para o aconchego. Esse sentimento é criado por objetos que possuem significado pessoal para o usuário. Assim, permitir a personalização do ambiente encoraja o indivíduo a reivindicar propriedade e a familiarizar-se com o lugar. Possuir "o seu lugar" é uma necessidade inerente ao ser humano, quer esteja ligada à noção de abrigo e proteção, ou relacionada à sua posição dentro da sociedade. Possuir a imagem do "seu espaço habitado" serve para afirmar a identidade (HEIDEGGER, 2002-2004).

A expressão "minha casa" possui duas vertentes principais: a proteção contra o mundo exterior e o apego a um lugar como fator de identidade. Todo o alojamento é, antes de tudo, um abrigo no interior do qual o indivíduo se sente protegido. A casa representa uma espécie de barreira às intromissões externas, porque limita e controla o número de interações e na sua construção, separa-se o mundo externo - inseguro e ameaçador - do interno protegido (FISCHER, 19--). Os cantos de uma casa são refúgios que asseguram um dos primeiros valores do ser: a imobilidade. Eles são locais seguros, onde é possível encontrar a paz. Certamente, fugindo do espaço real da casa e refugiando-se no canto, o ser humano toma consciência de existir (BACHELARD, 1998). Assim, os pormenores numa casa podem ser os signos de um contexto e conter atributos importantes do todo.

A casa é capaz de confortar o homem, enquanto lugar de apego, intimidade protegida, carregada de significados e lembranças. É um lugar onde a hierarquia dos espaços corresponde às necessidades. Um local onde uns se preocupam com os outros. Um espaço fechado e humanizado, dotado de valores e sentimentos.

No acolhimento institucional, há a necessidade de resgatar o ambiente familiar e o sentido de lugar, substituindo a família de origem pela oportunidade de convivência afetiva equilibrada e saudável - condição indispensável ao desenvolvimento humano. Os acessos aos recursos da comunidade, o envolvimento de membros da família de origem e a criação de uma atmosfera interior aconchegante, com ambientes personalizados, podem auxiliar nesse difícil processo de desenvolvimento da identidade de lugar e possibilitar a criação de uma familiaridade.

Dentre os reguladores espaciais que gerenciam a apropriação do ambiente construído, a privacidade é um dos mais presentes numa casa. Ela, segundo Snyder e Catanese (1984, p. 75), "[...] pode ser definida como o desejo de pessoas, grupos ou instituições de controlar o 


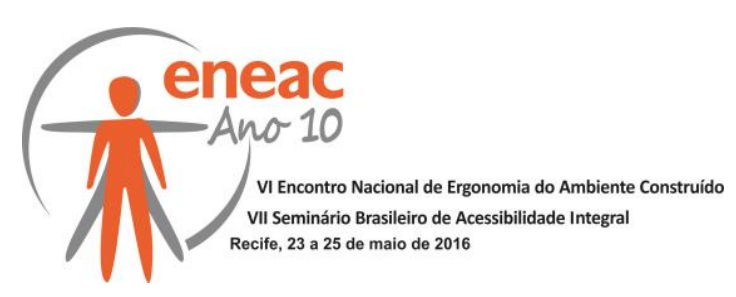

acesso a si mesmo e determinar quanto, como e quanta informação sobre elas mesmas será fornecida". É o mecanismo de controle que regula o isolamento ou distanciamento dos outros (ALTMAN, 1980).

Na relação entre privacidade e usuários, destaca-se que a dinâmica da institucionalização muitas vezes, reprime a privacidade, colocando a criança ou o adolescente num meio onde ele nunca será sujeito e muitas das dimensões de vida serão administradas do ponto de vista da conveniência da instituição. A supressão da privacidade é uma forma de barreira física, que limita os critérios de acessibilidade (orientabilidade, deslocamento, comunicação e uso) de acontecerem e dessa maneira distanciam o usuário do ambiente construído do modelo de casa - tão necessário ao seu crescimento e desenvolvimento.

Numa casa, as interações que se estabelecem entre sujeitos e lugares - entre a criança/adolescente e o quarto - não são uma mera relação física, mas uma relação carregada de sentido e mediada pelos demais sujeitos que o ocupam. Nesse sentido, na apropriação e constituição da privacidade, mescla-se a dimensão simbólica. Afinal, como afirma Bins Ely (2004, p. 21) a responsabilidade no projeto de ambientes deve ir além do conforto e da segurança - necessidades funcionais, "[...] pressupõe, também, compreender suas necessidades formais e estéticas a fim de assegurar um espaço agradável, de prazer e bem-estar". É nessa perspectiva mais global que se apresentam alguns resultados do estudo de caso realizado.

\section{ACESSIBILIDADE INTEGRAL}

É fato a importância das casas de acolhimento nas cidades brasileiras, já que essas atuam como substitutos (temporários ou não) da moradia de crianças e adolescentes em situação de vulnerabilidade social. Para que se alcance o tratamento de inclusão almejado pela legislação brasileira, a avaliação do ambiente construído sob um olhar mais abrangente de sua acessibilidade, neste estudo denominada como "acessibilidade integral", permite trabalhar para eliminar (ou minimizar) as barreiras que dificultam o processo de manter durante a institucionalização o sentido de pertencimento a algum lugar.

As barreiras atitudinais requerem maior complexidade de resolução, mas as físicas e informativas também dificultam ou limitam o uso do ambiente construído conforme as atividades cotidianas de uma casa, descaracterizando o objetivo da lei de incluir e não restringir os assistidos do cotidiano social.

Nesse contexto, a acessibilidade integral é uma visão de projeto que desenvolve objetos, ambientes e edificações levando em consideração a diversidade. O conceito de acessibilidade está relacionado aos conceitos de inclusão social e de cidadania (SANTOS, 1987). A arquitetura aborda a principio, a acessibilidade espacial que significa chegar a algum lugar de forma independente, segura e com um mínimo de conforto; entender a organização e as relações espaciais que este lugar estabelece; e participar de todas as atividades que ali se desenvolvem fazendo uso dos equipamentos disponíveis. Ela depende das condições ambientais de acesso à informação, das possibilidades de deslocamento e de uso, e da organização das atividades permitindo participar e estabelecer relações com as demais pessoas.

Nessa pesquisa, o conceito de acessibilidade segue Dischinger e Bins Ely (2004) que definiram quatro componentes básicos necessários para garantir acessibilidade, restringindo as barreiras físicas: orientabilidade, deslocamento, comunicação e uso. Essa pesquisa complementa o conceito com a investigação dos componentes como condicionantes de apropriação do ambiente construído. No caso do objeto de estudo, de permitir que o abrigo 


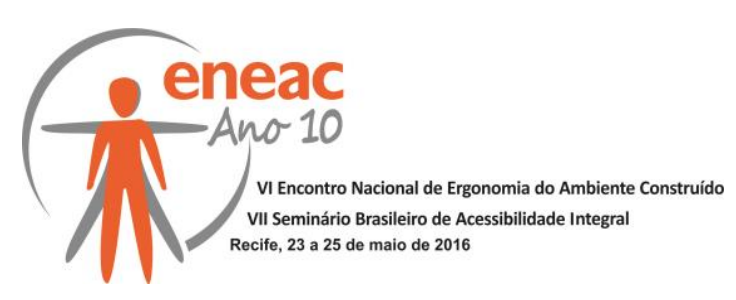

torne-se casa, criando condições para o sentido de pertencimento, de intimidade e privacidade.

A pesquisa quando aborda a acessibilidade integral pretende que além da espacial se alcance a apropriação do ambiente construído, transformando o espaço em lugar. $O$ conceito principal é o de garantir qualidade de vida à criança e ao adolescente em seu período de institucionalização. Numa visão polissêmica, a qualidade de vida é aproximada ao grau de satisfação encontrado na vida pessoal, social e ambiental. Pressupõe a capacidade de cada indivíduo de efetuar uma síntese positiva dos elementos envolvidos na sua vida, a partir do que a sociedade considera como padrão de conforto e bem-estar (MATURANA, 1995).

Numa casa, seja ela institucional ou não, provisória ou permanente, isso acontecerá mediante a possibilidade de cada indivíduo participar ativamente do cotidiano, de reconhecer a possibilidade de apropriar-se do ambiente construído. Alcançar a acessibilidade integral numa casa de acolhimento é compreendê-la não como a recriação de modelos ou simulacros de uma casa, e sim como um ambiente que possibilite a vivência de uma casa, reconhecendo ao mesmo tempo que esta é intrinsecamente institucional. $O$ objetivo é não desvincular a função institucional, mas tentar eliminar as barreiras que não permitem a sua aproximação com o conceito de casa, resumido na sensação de pertencimento e regulado pela privacidade.

Um importante fato que deve ser esclarecido é: a inclusão de crianças ou adolescente não é conquistada somente pela garantia de acesso espacial a todos os ambientes. É necessário promover o acesso e a compreensão da informação, a possibilidade de deslocamento livre de barreiras, e a garantia de uma participação efetiva nas atividades propostas. Por exemplo, num dormitório não é suficiente a criança apenas possuir a sua cama, mas ter o direito de livre acesso a roupeiros e outros objetos, ou a permissão para se isolar no recinto.

Os quatro componentes abordados por Dischinger e Bins Ely (2004) serão discutidos considerando essa abordagem. No estágio atual da pesquisa, há aproximações iniciais que almejam reiterar a compreensão que para alcançar a acessibilidade integral as pessoas precisam pertencer a um grupo e um lugar, como afirma Maturana (1995). A seguir, descrevem-se resumidamente os quatro componentes de acessibilidade avaliados.

Orientabilidade é saber onde se está, e para onde ir, a partir das informações arquitetônicas e dos suportes informativos (placas, sinais, letreiros etc.) de forma independente e autônoma. Em uma residência, é identificar os ambientes, reconhecendo-os a partir de memórias e associações: o meu dormitório, o meu local para guardar as roupas, o meu local para estudar.

Deslocamento é ter condições ideais de movimento ao longo de percursos horizontais ou verticais e seus componentes (salas, escadas, corredores, rampas, elevadores). 0 deslocamento é garantido através da supressão de barreiras físicas. Numa casa, em razão da segurança de crianças menores alguns ambientes tem restrição de acesso, como cozinhas e lavanderias. No entanto, as casas de acolhimento recebem usuários de diferentes idades e por isso, é necessário equilíbrio nessa restrição.

Comunicação é como se dão as condições de troca e intercâmbio de informações interpessoais, e entre pessoas e equipamentos de tecnologia assistiva, que permitem o ingresso e o uso da edificação. Numa casa, esse critério aparece na permissão das crianças e dos adolescentes de verem e se comunicarem com a rua e com todos os cômodos do ambiente construído, por exemplo.

O uso é dado pela possibilidade de participação do indivíduo nas atividades desejadas, utilizando os ambientes e equipamentos, sem que seja necessário conhecimento prévio. 


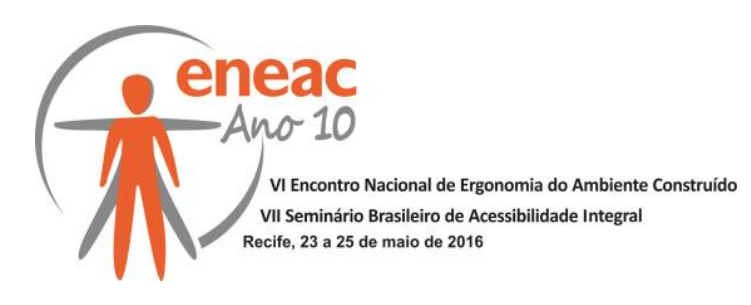

Numa casa, as atividades cotidianas de limpeza e arrumação fazem com que os usuários se sintam parte incluída.

\section{RESULTADOS: SUGESTÕES E RECOMENDAÇÕES}

O acolhimento institucional é a modalidade mais comum $(78,4 \%)$ no quadro nacional brasileiro e pode ser governamental ou não (IPEA; CONANDA, 2003). Esse tipo de instituição atende em média entre 20 e 25 crianças e adolescentes e, por isso, há dificuldades de proporcionar atendimento individualizado e em pequenos grupos, como indicado no artigo 92 do ECA.

Em Santa Catarina onde a pesquisa acontece, os últimos dados divulgados de 2014 mostraram cerca de 170 instituições de acolhimento institucional que atendem em torno de 1,5 mil crianças e adolescentes. Dessas, 440 são adolescentes entre 16 a 18 anos. Muitos deles destituídos do poder familiar, sem chances de retorno à família ou de serem adotados, por causa da idade.

Observa-se que há o distanciamento da vida comunitária (os internos vão às aulas em escola normal, mas em escassas atividades fora da instituição), e a crescente fragilidade ou rompimento dos vínculos com a família de origem ou estendida. O intuito é que crianças e adolescentes não sejam privados de liberdade. Para isso, o acolhimento institucional deveria possibilitar um "espaço para morar", até que a vida das crianças ou dos adolescentes fosse reestruturada, e ser uma instituição aberta, uma segunda casa que não aniquila, nem distorce ideias e metas.

Em análise dos dormitórios, constatou-se que em prol da organização da rotina, há rigor nos horários e afazeres, além da ausência de bens próprios. $O$ conjunto de bens individuais tem relação muito forte com o eu. Roupas e cosméticos, por exemplo, podem ser negados, confiscados ou guardados em locais inacessíveis e só disponibilizados com supervisão.

$\mathrm{Na}$ casa, o armário e suas prateleiras, a escrivaninha e suas gavetas, e outros tantos móveis são elementos fundamentais para a preservação da privacidade. Sem esses objetos, a vida íntima não teria um modelo de identidade. O espaço interior do armário, por exemplo, é um espaço de intimidade, que não se abre para qualquer um (BACHELARD, 1998).

Foi possível constatar que além da cama, os usuários não possuem espaços próprios dentro do dormitório. A restrição da privacidade e da posse de objetos faz aflorar comportamentos para confirmar a própria existência do interno. Trata-se, enfim, de modos de comunicação e expressão, os quais são também, formas de autoafirmação. Segundo Goffman (1996), os comportamentos rechaçados pelas "instituições totais" são expressões de alguém que tenta separar-se do local em que foi colocado.

É comum que sejam realizadas atividades para interação dos grupos, desrespeitando as características particulares de cada interno e estimulando os sentimentos de coletividade, em detrimento à individualidade, como se esse sentimento fosse totalmente maléfico.

É preciso ressaltar que a privacidade é um conceito em formação até a pré-adolescência. Mas, a privacidade requerida pelos abrigados e disponibilizada pelos funcionários era somente de horários distintos de banho para meninos e meninas. Nos dormitórios infantis, havia portas (mecanismo regulador da privacidade), mas raramente eram fechadas, conforme afirmaram os funcionários. No quarto dos adolescentes, porém, fechar a porta era permitido e havia cortinas nas janelas para regular a privacidade.

$\mathrm{Na}$ maioria das casas de acolhimento, o mobiliário encontrava-se em bom estado de conservação (figura 01). Era fruto de doações, e por isso respeitavam as normas de 


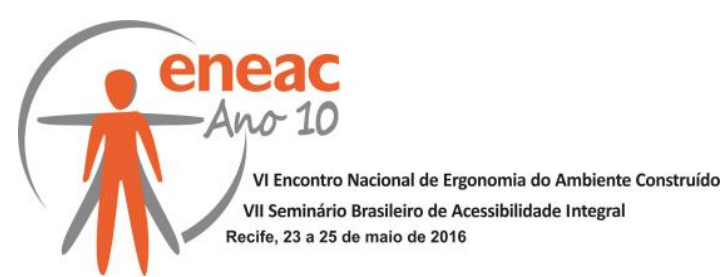

dimensionamento padrão. Foi possível constatar a necessidade de demarcação, através de colagem de figuras e outros recursos (figura 02).

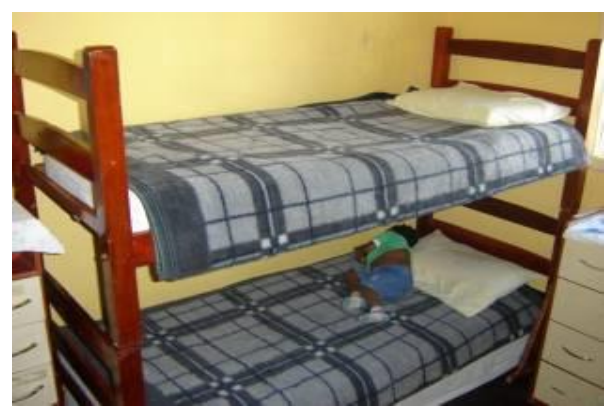

Figura 01 - Modelo de mobiliário em casa de acolhimento.

Fonte: SAVI, 2015.

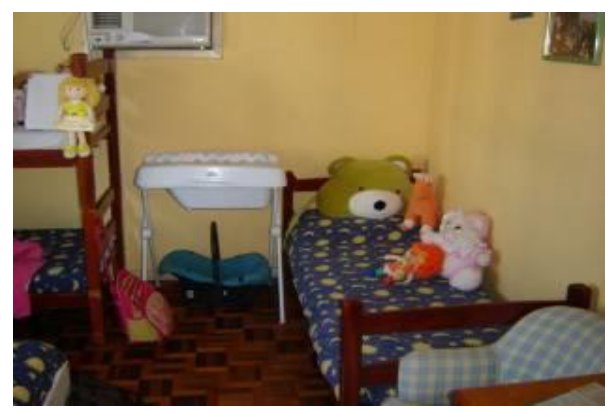

Figura 02 - Modelo de demarcação para privacidade.

Fonte: SAVI, 2015.

Uma das maneiras de se aproximar da relação com a casa e assim buscar inclusão é através do ambiente físico como instrumento para o abrigado participar da rotina doméstica. Essa sensação de lugar e aconchego é criada pela disponibilidade de possuir objetos pessoais com algum significado, por exemplo, bibelôs e fotografias. É importante que se permita a propriedade individual, e que haja locais próprios e de fácil acesso para que esses objetos sejam depositados. Sugere-se a colocação de prateleiras ou cômodas nos dormitórios, estantes abertas com nichos em alturas variadas, varais, quadros imantados ou similares, para a colocação de desenhos e fotografias (figura 03).

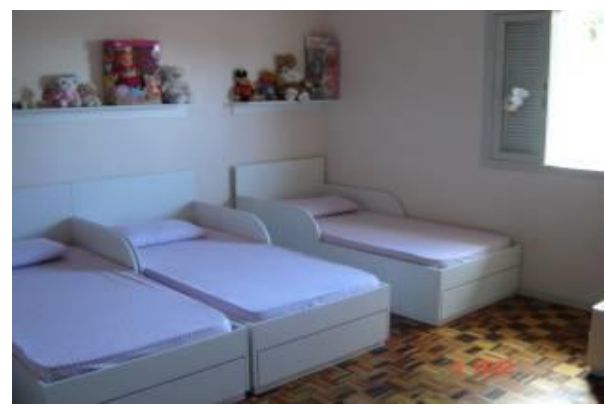

Figura 03 - Dormitório com prateleiras para demarcar espaço, mas em altura inacessível aos usuários.

Fonte: SAVI, 2015. 


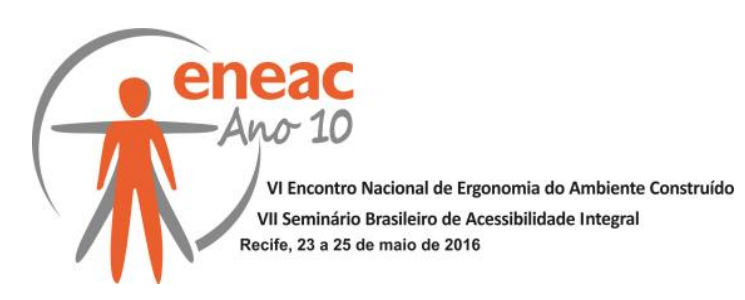

\section{CONSIDERAÇÕES FINAIS}

$O$ ideal seria que o acolhimento institucional tivesse o espaço pensado com a ambiência de uma casa, constituindo lugares que permitissem a vivência e o acúmulo de experiências tão necessárias para o crescimento e desenvolvimento humano de qualidade.

$\mathrm{Na}$ ambiência de uma casa, por exemplo, seria importante que as crianças e os adolescentes identificassem os usos e as possibilidades do espaço, inclusive definindo seus lugares preferidos: "a sua cama", "o seu espaço no roupeiro". As crianças possuem pouca necessidade de privacidade, mas com o crescimento as necessidades aumentam, tanto que a maneira mais comum de permanecer num ambiente, em especial o quarto, é com a porta fechada (ALTMAN, 1980). Nos quartos compartilhados isso não é possível. É importante então, que outras características sejam enfatizadas para amenizar a falta de privacidade, tais como: a personalização espacial, a propriedade das camas e de espaços nos armários.

A institucionalização consiste na substituição, provisória ou não, da estrutura física da casa e psicológica de família. Para tanto, o ambiente construído deve oferecer acessibilidade integral para o usuário participar e interagir, desenvolvendo novas competências cognitivas e sociais. Afinal, os programas de distribuição do espaço não apenas indicam os papéis que se espera das pessoas, mas também podem dificultar o exercício dos mesmos.

$\mathrm{Na}$ realidade atual brasileira, não se sabe precisamente quantas crianças e adolescentes em situação de vulnerabilidade social vivem institucionalizados. As respostas para: "Como vivem?" e "Por que estão longe da família?", ninguém as possui com clareza, mas é fácil reconhecer o quê precisam: uma casa e uma família.

Entende-se que é necessário reconsiderar a perspectiva institucional, investindo num processo de transformação que trabalha sobre as barreiras, sobretudo nos estigmas de depósito e instituição fadada ao fracasso. Afinal, a institucionalização, muitas vezes é a única alternativa para crianças e adolescentes e isso determina a necessidade de ações de superação desses trágicos estereótipos.

Como substituto da família, o acolhimento institucional absorve as problemáticas causadoras do afastamento das crianças e dos adolescentes do convívio familiar e lidam com um feixe de questões vivenciais extremamente difíceis e expressadas nos mais diversos traços comportamentais indicativos de sofrimento. Nessas instituições, as crianças e os adolescentes são internos numa casa provisória e o atendimento é essencialmente uma relação de trabalho entre funcionários e abrigados, por mais que haja vínculos afetivos. Isso pressupõe uma diferença significativa: o ato de cuidar não se insere no conjunto de práticas naturais, mas profissionais.

Essa realidade induz a um fator fundamental: deve-se pensar que o acolhimento institucional jamais substituirá os vínculos familiares. É outro tipo de cuidado e relação. Se é para melhor ou para pior, é impossível prever sem que haja um estudo aprofundado e individualizado da história de vida anterior e posterior à institucionalização.

Em contrapartida, o ambiente construído de uma casa pode em alguns aspectos, permitir acessibilidade e contribuir para o processo de inclusão social. O espaço de acolhimento institucional deve ser um lugar de apego e intimidade protegida, carregado de significados e lembranças, capaz de tornar-se um instrumento positivo ao desenvolvimento humano, guardando, nos ambientes, particularidades e características para permitir que a institucionalização seja pouco maléfica e não se torne um período de suspensão da vida. É importante que se caracterize como uma casa provisória, de atendimento individual e assim, descarte a coletividade, que afasta o acolhido da participação na rotina. 


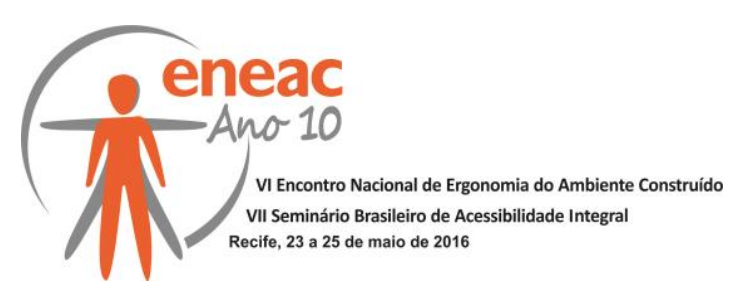

A acessibilidade integral nos espaços de acolhimento em face de situação de conflito existente, não é fator determinante para a inclusão social das crianças e adolescentes que nela habitam, mas certamente pode contribuir o seu bem estar e para a construção de sua identidade, sem a qual não há possibilidade de inclusão e cidadania.

\section{REFERÊNCIAS BIBLIOGRÁFICAS}

ALTMAN, Irwin; RAPOPORT, Amos; WOHLWILL, Joachim F (Eds.). Environment and culture. New York: Plenum, 1980. 351 p.

BACHELARD, Gaston. A poética do espaço. Tradução Antonio de Pádua Danesi. 3. ed. São Paulo: Ed. Martins Fontes, 1998. 242 p. (Original de 1993). (Coleção Tópicos).

BINS ELY, Vera Helena Moro. Acessibilidade Espacial - Condição Necessária para o Projeto de Ambientes Inclusivos. In: MORAES, Anamaria (org.). Ergodesign do Ambiente Construído e Habitado: Ambiente Urbano, Ambiente Público, Ambiente Laboral. Rio de Janeiro: IUsEr, 2004. 146pg.

BRASIL. [Estatuto da criança e do adolescente (1990)]. Estatuto da criança e do adolescente Lei 8.069/90. 4. ed. Rio de Janeiro: DP\&A, 2002. 156 p.

Lei Nacional de Adoção. Lei 12.010/09, de 03 de agosto de 2009.

DISCHINGER, Marta. BINS ELY, Vera Helena Moro. MACHADO, Rosângela. DAUFENBACH, Karine. SOUZA, Thiago Romano Mondini de. PADARATZ, Rejane. ANTONINI, Camile. Desenho Universal em Escolas: acessibilidade na rede escolar municipal de Florianópolis. - Florianópolis: PRELO, 2004. 190p. :il.

FISCHER, Gustave-N. Psicologia social do ambiente. Tradução Armando Pereira da Silva. Lisboa: Ed. Instituto Piaget, [19--]. 216 p.

GOFFMAN, Evering. Manicômios, prisões e conventos. Tradução Dante Moreira Leite. 5. ed. São Paulo: Ed. Perspectiva, 1996. 312 p. (Original de 1974). (Coleção debates).

HEIDEGGER, Martin. Ser e tempo. 12.ed. Petrópoles, RJ: Vozes; Bragança Paulista, SP: Universidade São Francisco, 2002 - 2004. 2 v. (Pensamento humano).

IPEA; CONANDA. Base de Dados da Rede SAC. Levantamento Nacional de Abrigos para Crianças e Adolescentes da Rede SAC. Brasília, out. 2003. (Relatório de pesquisa número 1). Disponível em: <http://www.portaldovoluntario.org.br>. Acesso em: 22 fev. 2007.

MATURANA, Humberto Romesín; VARELA, Francisco. A árvore do conhecimento: as bases biológicas do entendimento humano. Tradução Jonas Pereira dos Santos. Campinas: Psy II, 1995. $281 \mathrm{p}$.

NEWELL, A.F.; CAIRNS, A. Designing for Extraordinary Users. In: Ergonomics in Design, October, 1993.

OKAMOTO, Jun. Percepção Ambiental e comportamento: visão holística da percepção ambiental na arquitetura e na comunicação. São Paulo: Ed. Mackenzie, 2002. 261 p.

ORNSTEIN, Sheila. Avaliação Pós-Ocupação (APO) do Ambiente Construído. São Paulo: Editora da Universidade de São Paulo (EDUSP), 1992.

RAPOPORT, Amos. The Meaning of the Built Environment. Beverly Hills: Sage Publications, 1982.

RIBEIRO, Lúcia Gomes; MONT’ALVÃO, Claúdia. Ergonomia no Ambiente Construído. In: MORAES, Anamaria (org.). Ergodesign do Ambiente Construído e Habitado: Ambiente Urbano, Ambiente Público, Ambiente Laboral. Rio de Janeiro: IUsEr, 2004. 146 p. 


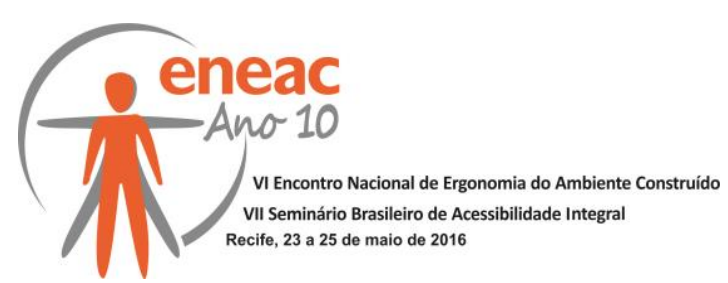

SANTOS, Milton. O espaço do cidadão. São Paulo: Nobel, 1987. Coleção espaços.

SNYDER, James C.; CATANESE, Anthony. Introdução à Arquitetura. Tradução Heloisa Frederico. Rio de Janeiro: Ed. Campus, 1984. p. 65-88.

TRANCIK, Anika M.; EVANS, Gary W. Spaces Fit for Children: Competency in the Design of Daycare Center Environments. In: Children's Environments. Colorado, v. 12, n. 03, 1995. p. 43-58. Disponível em: <http://www.colorado.edu/journals/cye>. Acesso em 23 set. 2006. 